\title{
Discrimination of Acinetobacter Genomic Species by AFLP Fingerprinting
}

\author{
PAUL JANSSEN, ${ }^{1}$ KEES MAQUELIN,${ }^{2}$ RENATA COOPMAN, ${ }^{1}$ INGELA TJERNBERG, ${ }^{3}$ \\ PHILIPPE BOUVET ${ }^{4}{ }^{\text {KAREL KERSTERS }}{ }^{1}$ AND LENIE DIJKSHOORN ${ }^{2 *}$ \\ Laboratorium voor Microbiologie, Universiteit Gent, B-9000 Ghent, Belgium ${ }^{1}$; Department of Medical Microbiology, \\ Leiden University Medical Center, NL-2300 RC Leiden, The Netherlands ${ }^{2}$; Department of Medical Microbiology,

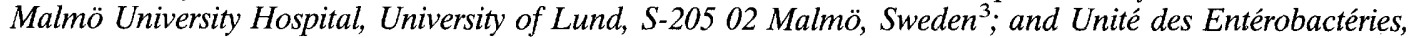 \\ Institut National de la Santé et de la Recherche Médicale, Institut Pasteur, F-75724 Paris Cedex 15, France
}

\begin{abstract}
AFLP is a novel genomic fingerprinting method based on the selective PCR amplification of restriction fragments. The usability of this method for the differentiation of genomic species in the genus Acinetobacter was investigated. A total of 151 classified strains (representing 18 genomic species, including type, reference, and field strains) and 8 unclassified strains were analyzed. By using a single set of restriction enzymes (HindIII and TaqI) and one particular set of selective PCR primers, all strains could be allocated to the correct genomic species and all groups were properly separated, with minimal intraspecific similarity levels ranging from 29 to 74\%. Strains belonging to genomic species 8 (Acinetobacter lwoffi sensu stricto) and 9 grouped together in one cluster. The closely related DNA groups 1 (Acinetobacter calcoaceticus), 2 (Acinetobacter baumannii), 3, and 13TU (sensu Tjernberg \& Ursing 1989) were clearly distinguishable, with intraspecific linkage levels above $50 \%$. Strains of the independently described genomic species 13BJ (sensu Bouvet \& Jeanjean 1989) and 14TU linked together at a relatively low level $(33 \%)$. Although a previous DNA-DNA hybridization study seemed to justify the unification of these genomic species, AFLP analysis actually divides the 13BJ-14TU group into three well-separated subgroups. Finally, four unclassified strains obtained from diverse sources and origins grouped convincingly together, with a similarity linkage level of approximately $50 \%$. These strains showed no similarities in their AFLP patterns with any of the other 155 strains studied and may represent a thus-far-undescribed Acinetobacter species. Based on these results, AFLP should be regarded as an important auxiliary method for the delineation of genomic species. Furthermore, because AFLP provides a detailed insight into the infraspecific structure of Acinetobacter taxa, the method also represents a highly effective means for the confirmation of strain identity in the epidemiology of acinetobacters.
\end{abstract}

The genus Acinetobacter was originally proposed more than 40 years ago by Brisou and Prévot (15) and is composed of nonmotile, gram-negative, saprophytic bacteria that are strictly aerobic, usually have a coccobacillary appearance, and show a fairly broad $\mathrm{G}+\mathrm{C}$ range of 38 to $47 \mathrm{~mol} \%$ in their genomic DNA $(41,46)$. The genus was placed originally within the family Neisseriaceae (41), but DNA-rRNA hybridization studies $(58,69)$ and phylogenetic analysis based on $16 \mathrm{~S}$ rRNA sequences (74) clearly showed that acinetobacters in fact belong to the $\gamma$ subclass of the class Proteobacteria, and subsequently, Rossau et al. (59) proposed to allocate the genus Acinetobacter to the family Moraxellaceae. This proposal has recently been supported by additional $16 \mathrm{~S}$ rRNA sequence data (25).

Acinetobacters are widespread in nature (reviewed in reference 66). They are indigenous organisms of various types of soils and waters $(1,8,23,54)$ and are occasionally found in foodstocks $(26,28)$. Although they are normal inhabitants of human skin (50) and are capable of transitory colonization of the upper respiratory tract (57), Acinetobacter spp. are considered to be normally nonpathogenic to healthy people. However, acinetobacters have been implicated in nosocomial infections in debilitated individuals $(3,34)$ and patients in intensivecare units are especially at risk $(2,27,29,60)$. In addition, there is a growing concern about the persistence and epidemic

\footnotetext{
* Corresponding author. Mailing address: Department of Medical Microbiology, Leiden University Medical Center, L4-P, P.O. Box 9600 , NL-2300 RC Leiden, The Netherlands. Phone: 31-71-526 39 31. Fax: 31-71-524 81 48. E-mail: dijkshoorn@rullf2.medfac.leidenuniv.nl.
}

spread of these organisms in the hospital environment because the strains involved are often resistant to multiple antibiotics $(4,16,20)$.

A number of extensive studies based on DNA-DNA hybridization $(11,12,48,65)$ resulted in the description of 18 DNA homology groups (DG; also called genomic species), seven of which have been named. In addition, a number of yet-ungrouped strains were described, implying the existence of additional genomic species $(11,12,32)$. Although many of the recognized Acinetobacter species could be differentiated by phenotypic criteria obtained from biochemical tests $(5,6,11-$ $13,44,45,64)$, by numerical analysis of cell envelope protein profiles (18), or by multilocus enzyme electrophoresis (14), accurate species delineation was in some cases difficult or impossible $(19,33)$. Elucidation of the ecology and pathology of the different genomic species of Acinetobacter requires methods for unambiguous identification of these groups. Unfortunately, the inadequacy of identification schemes based solely on phenotypic characteristics, including commercial identification systems, may lead to nomenclatural confusion (72).

Over the past few years, various molecular techniques have been employed for the phylogenetic analysis of the genus $\mathrm{Aci}$ netobacter, including PCR fingerprinting (73), amplified ribosomal DNA restriction analysis (ARDRA) $(17,67)$, analysis of amplified $16 \mathrm{~S}$ to $23 \mathrm{~S}$ ribosomal DNA intergenic spacer regions $(22,51)$, restriction analysis of amplified $r e c A$ gene sequences (53), a multiplex PCR assay that simultaneously targets RecAand 16S rRNA-encoding genes (52), tRNA fingerprinting (24), and DNA sequence analysis of genes encoding 16S rRNA (38, 56) or gyrase subunit B (75). However, most of these studies either included only strains of the first 12 genomic species 
originally described in 1986 by Bouvet and Grimont $(56,75)$ or contained only the type and/or reference strain of each genomic species $(51-53,73)$. In addition, some of the techniques used in these studies failed to delineate all investigated genomic species, and strains belonging to the same species could not always be differentiated from each other.

Recently, a novel PCR-based DNA fingerprinting technique, AFLP (70), was evaluated as a tool in bacterial taxonomy (39) and various conditions for a wide range of microorganisms, including Acinetobacter, were assessed. In two other studies, this method was shown to be very useful for the epidemiological typing of Acinetobacter strains $(21,40)$. In the present study, in which the phylogenetic structure of the genus Acinetobacter was analyzed by using 159 reference and type strains that were previously characterized by DNA-DNA hybridization experiments, two main issues were addressed: (i) to what extent are AFLP fingerprinting data in agreement with the previously obtained DNA-DNA hybridization data and (ii) are all genomic species currently recognized in the genus $\mathrm{Aci}$ netobacter distinguishable by a single method, AFLP?

\section{MATERIALS AND METHODS}

Bacterial strains and culture conditions. All strains studied are listed in Table 1. The collection comprised type and reference strains originally obtained from public culture collections and strains collected from clinical and environmental sources. Some strains were kind gifts from P. Kämpfer, Institut für Angewandte Mikrobiologie, Justus-Liebig-Universität Giessen, Giessen, Germany, and P. Gerner-Smidt, Statens Seruminstitut, Copenhagen, Denmark. All strains have been identified to the genomic species level by DNA-DNA hybridization analysis and were (with few exceptions) used in previous studies $(10-12,18,32,48,65)$. Five strains, CIP 64.2 (from DG 13BJ [sensu Bouvet \& Jeanjean 1989]), K. Irino 105/85 (from DG 14BJ), CCUG 14816 (from DG 14BJ), CIP 70.18 (from DG 16), and SEIP Ac 87.314 (from DG 17) (listed in Table 1 as LUH 1717, LUH 1726, LUH 1727, LUH 1731 , and LUH 1736 , respectively), were received from two different sources and were included in duplicate (received as ATCC 17905 , Malmoe 99681, Malmoe 99871, and Malmoe 13693 from the collection of one of the authors [I.T.] and as SEIP Ac 87.314, obtained from P. Kämpfer, respec tively; duplicate strains are not listed in Table 1). For DNA preparation, bacteria cultures were grown aerobically on nutrient agar containing nutrient broth (Gibco BRL) supplemented with $1.5 \%$ (wt/vol) Bacto Agar (Difco) at $28^{\circ} \mathrm{C}$. Strains were stored at $-70^{\circ} \mathrm{C}$ as grown cultures, to which $10 \%$ glycerol was added prior to freezing.

Isolation of chromosomal DNA. Acinetobacter DNAs were prepared by the method of Pitcher et al. (55) with minor modifications. The entire procedure for the extraction and purification of Acinetobacter DNAs has been reported elsewhere (39). Prepared DNAs were run on a $1 \%$ agarose gel in the presence of ethidium bromide $\left(0.5 \mu \mathrm{g} \mathrm{ml}^{-1}\right)$ to check for integrity and were stored at $-20^{\circ} \mathrm{C}$

Preparation of template DNA for PCR amplification. Digestion of genomic DNAs with the restriction endonucleases HindIII and TaqI and subsequent ligation of restriction half-site-specific adaptors to all restriction fragments was done as outlined previously (39). Adaptor design has been described in detail by Zabeau and Vos (76) and Vos et al. (70). The HindIII and TaqI half-site-specific adaptors consisted of equimolar mixtures of the partly complementary oligonucleotides 5'-CTCGTAGACTGCGTACC-3' and 5'-AGCTGGTACGCAGTC $3^{\prime}$, and $5^{\prime}$-GACGATGAGTCCTGAC-3' and 5'-CGGTCAGGACTCAT-3', re spectively. All DNA templates were stored at $-20^{\circ} \mathrm{C}$.

AFLP reactions. Selective amplification of restriction fragments was achieved by the use of primers H01 (5'-GACTGCGTACCAGCTTa-3') and T05 (5'-GA TGAGTCCTGACCGAaa- $3^{\prime}$ ), which have one or two adenines as $3^{\prime}$ extensions (indicated in lowercase letters), respectively. The notation of the primers is according to Janssen et al. (39). Amplification reactions, as well as the 5' end labeling of the $\mathrm{H} 01$ primer with ${ }^{32} \mathrm{P}$, were done as described by Zabeau and Vos (76) with some modifications (39)

Data acquisition. All procedures and equipment have been reported elsewhere (39). Brieffy, samples of the amplification reaction mixtures were loaded on a $5 \%$ denaturing polyacrylamide gel and PCR-amplified products were separated electrophoretically. Following electrophoresis, gels were dried and exposed to a 35-by 43-cm Hyperfilm-MP film (Amersham). Autoradiograms were scanned by a high-resolution densitoscanner, and images were maintained as TIFF files. Raw data were further processed with GelCompar version 3.1 software (Applied Maths b.v.b.a., Kortrijk, Belgium).

Numerical analysis of banding patterns. Digital images were normalized as outlined by Janssen et al. (39). The Acinetobacter calcoaceticus type strain, ATCC 23055 (Table 1), was used as the reference strain because AFLP analysis of this strain (under the conditions given above) generated a banding pattern displaying evenly distributed and well-separated bands over the entire length of the gel.
From each reference track, the same 26 bands were used for alignment. All results presented in this study were obtained by combining a total of eight polyacrylamide gels. The similarity between each pair of AFLP patterns was calculated by using the Pearson product moment correlation coefficient $(r)$. Strains were clustered by using the unweighted-pair group method with arithmetic averages (UPGMA) (62). Using GelCompar, we calculated a standard deviation for every branch of the dendrogram. These standard deviations are indications of the significance and stability of the formed clusters and are given as \pm values in Table 2 or when linkage levels are discussed in the text.

\section{RESULTS AND DISCUSSION}

Reproducibility of AFLP with Acinetobacter genomic DNAs. Small variations in background intensities and slightly deviating electrophoretic conditions may introduce minimal differences in the correlation values between reference tracks (obtained from strain ATCC $23055^{\mathrm{T}}$; see Materials and Methods). However, following normalization and subtraction of background values, the similarity levels of banding patterns obtained from multiple specimens of strain ATCC $23055^{\mathrm{T}}$, included in several lanes of each gel to allow inter- and intragel comparison, were at least 90 and $95 \%$, respectively (results not shown). The same similarity level $(>90 \%)$ was obtained between duplicate strains analyzed on different gels (not shown). In this report as well as in previous studies $(36,39)$ these intraand intergel-specific correlation values between reference samples or between duplicate strains were considered threshold values for the reproducible discrimination of genomic species by cluster analysis of AFLP patterns.

Correlation of AFLP results with existing taxonomic data. (i) Identification of Acinetobacter genomic species by AFLP. Strains that belong to the same genomic species (or DG) always grouped together in one particular AFLP cluster (Fig. 1). Each AFLP cluster could be outlined as a set of strains that showed an average linkage level ranging from 29 to $74 \%$, with most of the actual values around $45 \%$ (Fig. 1 and Table 2). Genomic species DG 11, DG 14BJ, and DG 17BJ showed a relatively low linkage level of about $(38.1 \pm 4.4),(40.6 \pm 6.3)$, and $(42.4 \pm 0.0) \%$, respectively. The exceptionally low linkage level of $A$. johnsonii (DG 7) strains ([29.4 \pm 5.5$] \%$ ) was mainly due to the inclusion of a strain isolated from activated sludge (10) (see below). Exclusion of this strain would result in a linkage level for this group of $(44.7 \pm 5.5) \%$ (Table 2$)$. On the whole, all Acinetobacter genomic species that are currently recognized as distinct taxa (excluding DG 8-9 and DG 13BJ14TU) were easily distinguished by AFLP (Fig. 1).

(ii) Interspecific phylogenetic relationships in the genus Acinetobacter. The results obtained from three independent DNA-DNA hybridization studies $(11,12,65)$, including either reciprocal measurements between reference strains or measurements between a particular reference strain and heterologous strains from other genomic species, suggested close relationships among some of the genomic species. In particular, this appeared to be the case for (i) genomic species $1(A$. calcoaceticus), 2 (A. baumannii), 3, and 13TU (sensu Tjernberg \& Ursing 1989); (ii) genomic species 4 (A. haemolyticus) and 6; (iii) genomic species 10 and 11; (iv) genomic species 8-9 ( $A$. lwoffii) and 15TU; and (v) genomic species 15BJ, 16BJ, and 17BJ. The linkages among these genomic species could be fully corroborated by extensive phenotypical studies $(5,44)$ and, to a lesser extent, by cell envelope protein profiling (18), chemotaxonomic analysis (43), restriction fragment length polymorphism analysis of rRNA-encoding genes by using ARDRA (67), and DNA sequence analysis of $16 \mathrm{~S}$ rRNA- and GyrBencoding genes $(38,75)$. In contrast, although AFLP fingerprinting groups the highly related genomic species $1,2,3$, and $13 T U$ together in one cluster, it does so only at a very low linkage level (22\%), and this cluster also contains $A$. junii (DG 
TABLE 1. Strains used ${ }^{a}$

\begin{tabular}{|c|}
\hline Strain \\
\hline $\begin{array}{l}\text { Genomic species } 1 \\
\quad(\text { A. calcoaceticus }) \\
\text { RUH 2201 } \\
\text { RUH } 54^{\text {Tb }}{ }^{b} \\
\text { RUH } 584^{b} \\
{\frac{\text { RUH } 944^{b}}{}}^{\text {RUH } 582^{b}} \\
{\text { RUH } 2202^{b}}^{b} \\
\text { RUH } 2203\end{array}$ \\
\hline
\end{tabular}

Genomic species 2

$$
\text { (A. baumannii) }
$$

RUH 1093

RUH 332

RUH 210

RUH 128

RUH 97

RUH 447

$\underline{\text { RUH } 414^{b}}$

Genomic species 3

RUH $2204^{b}$

RUH 502

${\text { RUH } 1163^{b}}^{b}$

RUH 2205

RUH $1020^{b}$

${\underline{\mathrm{RUH}} 509^{b}}^{b}$

RUH 37

RUH 408

RUH $468^{b}$

RUH 56

RUH 532

RUH $2206^{b}$

Genomic species 4

(A. haemolyticus)
RUH 2213
RUH 415
RUH 55
RUH 406
RUH 2215
RUH 44
RUH 2214

Designation as received and/or other designations

Source

\begin{tabular}{ll}
${\frac{\operatorname{ATCC} 23055^{\mathrm{T}, c}}{\operatorname{LMD~22.17}}, 2^{d}}^{d}$ & Soil \\
\hline $4^{d}$ & Soil \\
$5^{d}$ & Soil \\
$6^{d}$ & Intravenous catheter \\
$42^{c}, 7^{d}$ & Soil \\
$132^{c}, 8^{d}$ & Wound \\
& Wound
\end{tabular}

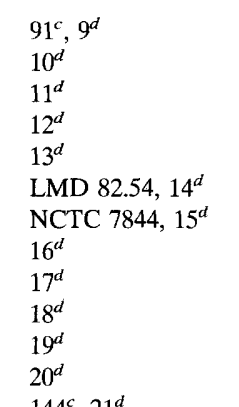

Sputum

Wound

Wound

Toe web

Bronchus

Not known

Not known

Urine

Wound

Urine

Pus

Sputum

Wound

Urine

Wound

Urine

Urine

Wound

Sputum

Urine

Sputum

Urine

Urine

Blood

Urine

Urine

Urine

Sputum

Blood

Sputum

Sputum

Sputum

Catheter tip

Ear

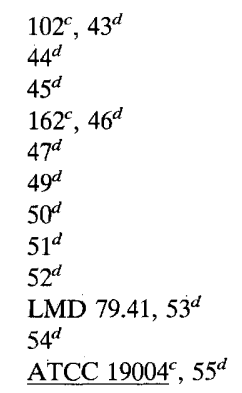

Wound
Drain
Toe web
Wound
Bronchus
Bronchus
Blood
Not known
Urine
Not known
Urine
Cerebrospinal fluid

$197^{c}, 56^{d}$
$57^{d}$
LMD $70.9,58^{d}$
Gilardi $2890,59^{d}$
ATCC $17906^{\mathrm{T}, c}, 60^{d}$
$61^{d}$
$61^{c}, 62^{d}$

Wound

Pus

Not known

Not known

Sputum

Air

Not known
TABLE 1-Continued

\begin{tabular}{ccc}
\hline Strain & $\begin{array}{c}\text { Designation as received } \\
\text { and/or other designations }\end{array}$ & Source \\
\hline
\end{tabular}

Genomic species 5

(A. junii)
RUH 2228
RUH 204
RUH 383
RUH 2229
RUH 2230
Genomic species 6
RUH 2867
LUH 286

ATCC $17908^{\mathrm{T}, c}, 63^{d} \quad$ Urine

$64^{d} \quad$ Blood

$65^{d} \quad$ Not known

$124^{c}, 66^{d} \quad$ Surgical gown

$178^{c}, 67^{d} \quad$ Water

ATCC $17979^{\circ}, 68^{d} \quad$ Throat

MGH 97923, 39e Urine

Genomic species 7

(A. johnsonii)

RUH $2231^{\mathrm{T}}$

RUH 2233

RUH 2855

RUH 2856

RUH 2857

RUH 2858

RUH 2232

RUH 2859

LUH 540

ATCC $17909^{\mathrm{T}, c}, 69^{d} \quad \mathrm{Gu}$

$92^{c}, 70^{d} \quad$ Urine

$68^{c}, 71^{d} \quad$ Urine

$97^{c}, 72^{d} \quad$ Urine

$112^{c}, 73^{d} \quad$ Urine

$134^{c}, 74^{d} \quad$ Urine

$153^{c}, 75^{d} \quad$ Feces

$137^{c}, 76^{d} \quad$ Urine

LMD 90.19, 210A $\quad$ Activated sludge

Genomic species 8-9

(A. Iwoffii)

RUH $2219^{\mathrm{Tb}}$

RUH 551

RUH 45

RUH $2221^{b}$

RUH 548

RUH $74^{b}$

RUH 302

RUH $1104^{b}$

RUH $1115^{b}$

RUH 549

RUH 303

RUH 709

RUH 2220

LUH $1710^{b}$

LUH $1711^{b}$

LUH $1712^{b}$

LUH $1713^{b}$

\section{LUH $1714^{b}$}

LUH 1715

Genomic species 10

RUH 2222

RUH 2223

RUH 2224

Genomic species 11

RUH 2234

RUH 2861

RUH 1050

RUH 2236

RUH 2235

RUH 2860

LUH 287

${\text { NCTC } 5866^{\mathrm{T}, c}, 77^{d}}_{78^{d}}$
$79^{d}$
$44^{c}, 80^{d}$

$44^{c}, 80^{d}$

$82^{d}$

$83^{d}$

$84^{d}$

$85^{d}$

$86^{d}$

$87^{d}$

$88^{d}$

$202^{c}, 89^{d}$

$62^{g}$, CIP 70.31, ATCC $9957^{\circ}$

$63^{g}$, SEIP Ac84.203

$64^{\circ}$, SEIP 14.84

$65^{\circ}$, CIP A162, ATCC

$17968^{\circ}$

$66^{\circ}$, CIP 70.19, ATCC

17984

$67^{g}$, SEIP 4.83

Not known

Not known

Blood

Prostate secretion

Eye

Not known

Skin

Skin

Skin

Urine

Door

Wound

Urine

Gangrenous lesion

Chicken

Sperm culture

Conjunctivitis

Not known

Pus

$198^{c}, 90^{d}$

113:2 $2^{c}, 91^{d}$

Urine

ATCC $17924^{c}, 92^{d} \quad$ Not known

$174^{c}, 93^{d}$

Contact lens

CIP 63.46 , ATCC 11171, Not known $94^{d}$

LMD 81.109, $95^{d}$

Not known

$51^{c}, 96^{d}$

$210^{c}, 97^{d}$

$58 \mathrm{~b}^{c}, 98^{d}$

MGH 97931, 225

Urine

Wound

Wound

Genomic species 12

(A. radioresistens)

RUH 2225

RUH 2864

RUH 2226

RUH 2862

RUH $2865^{\mathrm{T}}$

RUH 2863

RUH 2227

RUH 3517

\section{$109^{c}, 99^{d}$}

SEIP $12.81^{c}, 100^{d}$

$152^{c}, 101^{d}$

$26^{c}, 102^{d}$

FO-1 ${ }^{\mathrm{T}, c}$, IAM $13186^{\mathrm{T}}, 103^{d}$

$73^{c}, 104^{d}$

$50^{c}, 105^{d}$
Sputum 
TABLE 1-Continued

\begin{tabular}{|c|c|c|}
\hline Strain & $\begin{array}{l}\text { Designation as received } \\
\text { and/or other designations }\end{array}$ & Source \\
\hline \multicolumn{3}{|c|}{$\begin{array}{l}\text { Genomic species } \\
\text { 13BJ }\end{array}$} \\
\hline LUH $1717^{b}$ & $\begin{array}{l}82^{h}, \text { CIP } 64.2, \text { ATCC } \\
17905, \text { B } 30 \text { (also known } \\
\text { as the type strain of } \\
\text { Achromobacter } \\
\text { conjunctivae) }\end{array}$ & Conjunctiva \\
\hline LUH $1718^{b}$ & $134^{h}, \underline{\text { SEIP } 5.84}$ & Blood \\
\hline LUH $1719^{b}$ & $376^{h}, \mathrm{~K}$. Irino $214 / 84$ & Cerebrospinal fluid \\
\hline$\overline{\text { LUH } 1720^{b}}$ & $496^{h}$, SEIP Ac86.66 & Skin \\
\hline LUH $1722^{b}$ & $943^{h}$, SEIP Ac87.315 & $\begin{array}{l}\text { Unknown human } \\
\text { origin }\end{array}$ \\
\hline LUH $1723^{b}$ & $1001^{h}, \underline{\text { SEIP Ac87.348 }}$ & Skin \\
\hline LUH $1724^{b}$ & $1158^{h}$, SEIP Ac88.239 & Skin \\
\hline${\underline{\text { LUH }} 1725^{b}}^{b}$ & $1191^{h}$, P. Osterrieth 190 & Catheter \\
\hline \multicolumn{3}{|c|}{$\begin{array}{c}\text { Genomic species } \\
14 \mathrm{TU}\end{array}$} \\
\hline$\underline{\mathrm{RUH}} 2216^{b}$ & $71^{c}, 117^{d}$ & Conjunctiva \\
\hline${\underline{\text { RUH } 2866^{b}}}^{b}$ & $114^{c}, 118^{d}$ & Cerebrospinal fluid \\
\hline$\underline{\text { RUH } 2217^{b}}$ & $101^{c}, 119^{d}$ & Conjunctiva \\
\hline RUH $2218^{b}$ & ATCC $17905^{c}, 120^{d}$ & Conjunctiva \\
\hline${\underline{\text { RUH } 3206^{b}}}^{b}$ & "from patient $\mathrm{H}^{\prime \prime i}$ & Sputum \\
\hline${\underline{\text { RUH } 3207^{b}}}^{2}$ & "from patient $\mathrm{I} " i$ & Sputum \\
\hline${\underline{\mathrm{RUH}} 3211^{b}}^{b}$ & $04 / 90 \mathrm{VI}^{i}$ & $\begin{array}{l}\text { Respiratory } \\
\text { flowmeter }\end{array}$ \\
\hline \multicolumn{3}{|c|}{$\begin{array}{c}\text { Genomic species } \\
13 T U\end{array}$} \\
\hline RUH $2210^{b}$ & $\underline{\operatorname{ATCC} 17903^{c}}, 106^{d}$ & Not known \\
\hline RUH $2624^{b}$ & $107^{d}$ & Skin (forehead) \\
\hline RUH 2285 & $108^{d}$ & Bronchus \\
\hline$\underline{\text { RUH } 2376^{b}}$ & $109^{d}$ & Sputum \\
\hline${\underline{\text { RUH }} 503^{b}}^{b}$ & $110^{d}$ & Urine \\
\hline RUH 2041 & $111^{d}$ & Post mortem \\
\hline RUH $2284^{b}$ & $112^{d}$ & Bronchus \\
\hline${\underline{\text { RUH } 2627^{b}}}^{b}$ & $113^{d}$ & Rectum \\
\hline RUH 412 & $114^{d}$ & Blood \\
\hline RUH 2211 & $100^{c}, 115^{d}$ & Gastric fistula \\
\hline RUH 2212 & $165^{c}, 116^{d}$ & Urine \\
\hline \multicolumn{3}{|c|}{$\begin{array}{l}\text { Genomic species } \\
14 \mathrm{BJ}\end{array}$} \\
\hline LUH 1726 & $382^{h}, \mathrm{~K}$. Irino $105 / 85$ & Conjunctiva \\
\hline LUH 1727 & $\begin{array}{l}513^{h}, \text { CCUG } 14816 \\
\text { Gilardi GLG } 4638\end{array}$ & Wound \\
\hline LUH 1728 & $\begin{array}{l}743^{h}, \text { RE Weaver CDC } \\
\text { E655 }\end{array}$ & Not known \\
\hline \multicolumn{3}{|c|}{ Genomic species } \\
\hline LUH 1729 & $\begin{array}{l}79^{h} \text {, M.M.Adam Ac606 } \\
\text { 180:40 va. }\end{array}$ & Skin \\
\hline LUH 1730 & $81^{h}$, SEIP 23.78 & Urine \\
\hline \multicolumn{3}{|c|}{ Genomic species } \\
\hline LUH 1090 & $151 a^{c}, \mathrm{MGH} 98795$ & Urine \\
\hline LUH 1091 & 118, MGH 98794 & Feces \\
\hline \multicolumn{3}{|c|}{$\begin{array}{l}\text { Genomic species } \\
16 \mathrm{BJ}\end{array}$} \\
\hline LUH 1731 & $\begin{array}{l}78^{h}, \text { CIP } 70.18, \text { ATCC } \\
17988\end{array}$ & Urine \\
\hline LUH 1732 & $673^{h}$, SEIP Ac87.123 & Urine \\
\hline LUH 1734 & $1211^{h}$, P. Osterrieth 312 & Feces \\
\hline \multicolumn{3}{|c|}{$\begin{array}{l}\text { Genomic species } \\
17 \mathrm{BJ}\end{array}$} \\
\hline LUH 1735 & $641^{h}$, SEIP $2 / 87$ & Wound \\
\hline LUH 1736 & $942^{h}$, SEIP Ac87.314 & Leg ulceration \\
\hline
\end{tabular}

TABLE 1-Continued

\begin{tabular}{lll}
\hline \multicolumn{1}{c}{ Strain } & \multicolumn{1}{c}{$\begin{array}{c}\text { Designation as received } \\
\text { and/or other designations }\end{array}$} & \multicolumn{1}{c}{ Source } \\
\hline $\begin{array}{l}\text { Unclassified strains } \\
\text { LUH } 1737^{b}\end{array}$ & $80^{h}$, SEIP 14.83 & Blood \\
LUH $1740^{b}$ & $930^{h}, \underline{\text { SEIP Ac87.302 }}$ & Tracheal exudate \\
LUH $1741^{b}$ & $944^{h}, \underline{\text { SEIP Ac87.316 }}$ & Wound \\
$\underline{\text { LUH } 1742^{b}}$ & $1240^{h}$, RUH 65 & Clinical specimen \\
$\underline{\text { LUH } 1469^{b}}$ & MGH 99613, 10095 & Abscess \\
$\underline{\text { LUH } 1470^{b}}$ & MGH 99614, 10169 & Sputum \\
$\underline{\text { LUH } 1471^{b}}$ & MGH 99896, 5804 & Blood \\
$\underline{\text { LUH } 1472^{b}}$ & MGH 99685, 10090 & Ulcer \\
\hline
\end{tabular}

${ }^{a}$ LUH and RUH, collection L. Dijkshoorn, Leiden University Medical Center, Leiden, The Netherlands; ATCC, American Type Culture Collection, Rockville, Md.; LMD, LMD Culture Collection, University of Technology, Delft, The Netherlands; NCTC, National Collection of Type Cultures, London, United Kingdom; CCUG, Culture Collection, University of Göteborg, Göteborg, Sweden; CIP, Collection de l'Institut Pasteur, Paris, France; SEIP, Service des Entérobactéries de l'Institut Pasteur, Paris, France; IAM, Institute of Applied Microbiology, The University of Tokyo, Tokyo, Japan; MGH, Collection of Malmoe General Hospital, Malmoe, Sweden.

${ }^{b}$ AFLP patterns are given in Fig. 2 to 4 under the underlined designations.

${ }^{c}$ Designation and strain used by Tjernberg and Ursing (65).

${ }^{d}$ Serial number used by Dijkshoorn et al. (18).

e Designation used by Gerner-Smidt et al. (33).

${ }^{f}$ Designation used by Bonting et al. (10).

${ }^{g}$ Designation used by Bouvet and Grimont (12).

${ }^{h}$ Designation used by Bouvet and Jeanjean (11).

${ }^{i}$ Designation used by Horrevorts et al. (35).

${ }^{j}$ Strain number used by Gerner-Smidt and Tjernberg (32).

5) (Fig. 1). Furthermore, although DGs $15 \mathrm{BJ}, 16 \mathrm{BJ}$, and 17BJ can be found in close proximity, genomic species $4,6,10$, and 11 are scattered throughout the AFLP dendrogram (Fig. 1). These findings indicate that the present AFLP methodology is of limited value in the determination of interspecific relationships in the genus Acinetobacter.

AFLP analysis of the Acb complex. Because interspecific DNA homology values suggested a close relationship between genomic species 1 (A. calcoaceticus sensu stricto), 2 (A. baumannii), 3 , and $13 \mathrm{TU}(12,65)$, and because biochemical tests were often inadequate for the proper discrimination of individual strains $(5,6,13,33)$, these species were lumped into one complex, also known as the $A$. calcoaceticus-A. baumannii (Acb) complex. Recently, four strains forming two new distinct groups were included in the Acb complex (32). Several authors have addressed the intricacy of this complex by using molecular typing methods, including restriction analysis of rRNA-encoding genes (22) and ribotyping (30), pulsed-field gel electrophoresis of large genomic restriction fragments (61), electrophoretic analysis of enzymes (14), repetitive extragenic palindromic sequence-based PCR (63), and tRNA spacer fingerprinting (24). In general, the use of these methods enabled the differentiation of DGs 1,2,3, and 13TU, although some methods failed to separate $A$. calcoaceticus (DG 1 ) from DG 3 or A. baumannii (DG 2) from DG 13TU $(14,24)$.

A total of 64 strains of the Acb complex with known DNA group affiliations were analyzed by AFLP fingerprinting. Strains representing $A$. calcoaceticus, A. baumannii, and the genomic species 3 and 13TU clearly grouped in four separate AFLP clusters at an intraspecific similarity of 50 to $60 \%$ (Fig. 1 and Table 2). Four strains (designated LUH 1469 to 1472 [Table 1]), which genotypically belong to the Acb complex but are distinct from the four other genomic species (32), grouped separately in two clusters, UG1 and UG2, of two strains each (Fig. 1 and 2). Pairwise grouping of these strains by AFLP analysis was in agreement with the observations made by 


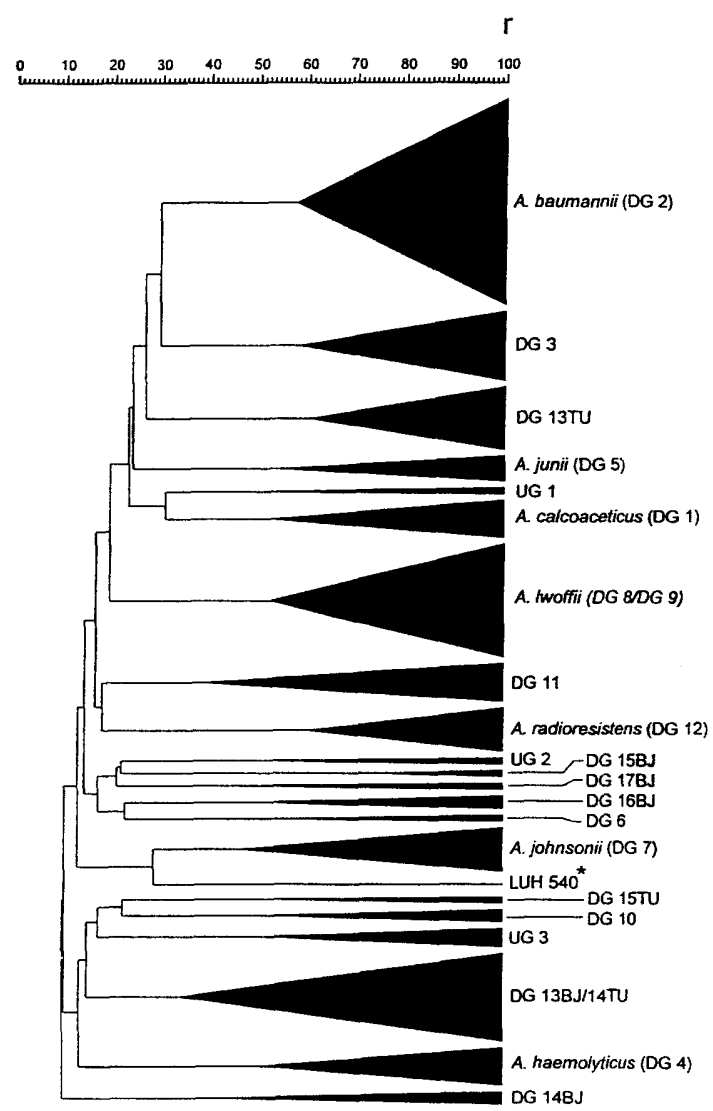

FIG. 1. Cluster analysis of 159 Acinetobacter strains with HindIII-TaqI-digested genomic DNAs. All amplification reactions were performed with the same primerset, H01-T05 (see Materials and Methods). AFLP patterns used for numerical analysis were derived from eight different gels. Genomic species are given as DGs. UG, ungrouped strains; *, deviating $A$. johnsonii strain (DG 7); $r$, Pearson product moment correlation coefficient. The dendrogram was constructed by using UPGMA.

Gerner-Smidt and Tjernberg (32), whose findings were based on DNA hybridization experiments. However, phylogenetic relationships that were reported between the two new groups (UG1 and UG2) and the rest of the Acb complex (22, 24, 32, 38) could not be demonstrated by AFLP.

AFLP analysis of $A$. haemolyticus, $A$. junii, and $A$. johnsonii. In 1986, Bouvet and Grimont (12) proposed to name genomic species 4, 5, and 7 A. haemolyticus, $A$. junii, and $A$. johnsonii, respectively.

(i) A. haemolyticus. Strains belonging to $A$. haemolyticus are occasionally isolated from patients and the hospital environment (12). Seven $A$. haemolyticus strains, including the reference strains RUH 2213 and RUH $2215^{\mathrm{T}}$ (= ATCC 17906 ${ }^{\mathrm{T}}$ ) (Table 1) from two independent DNA hybridization studies, were analyzed with AFLP and could be grouped together at a linkage level of $(50.6 \pm 3.2) \%$ (Fig. 1 and Table 2$)$.

(ii) A. junii. A. junii is predominantly found in clinical specimens (12) and has been associated with outbreaks in neonates $(7,68)$. Five $A$. junii strains were subjected to AFLP analysis and grouped together at a similarity level of $(54.7 \pm 7.5) \%$ (Fig. 1 and Table 2). Although this group can be found as part of the Acb complex in the large dendrogram (Fig. 1), it is not possible to determine interspecific relationships by the current AFLP methodology and none of the previous taxonomic studies have indicated a particular relationship between $A$. junii and members of the complex. The positioning of $A$. junii in the dendrogram (Fig. 1) should therefore be regarded as purely incidental.

(iii) $A$. johnsonii. A. johnsonii is occasionally isolated from the hospital environment (31), but its etiological role in human infection remains unclear. $A$. johnsonii has also been associated with biological phosphate removal in activated sludge systems (23), although the role of acinetobacters in these processes has recently been de-emphasized $(9,71)$. A total of nine $A$. johnsonii strains were analyzed by AFLP fingerprinting. Eight strains from clinical sources convincingly grouped together at $(44.7 \pm$ $5.5) \%$ similarity, but the remaining strain, LUH 540 (= LMD 90.19 [Table 1]), only linked at (29.4 \pm 5.5$) \%$ (Fig. 1 and Table 2 ). This strain was originally isolated from activated sludge as strain $210 \mathrm{~A}$ and could be identified as $A$. johnsonii by phenotypic methods and DNA hybridization $(5,10)$. The AFLP banding pattern of this strain strongly deviated from those of the other $A$. johnsonii strains (Fig. 1; patterns not shown), in spite of the apparently high DNA homology with the $A$. johnsonii type strain ATCC 17909 (with a $\Delta T_{m}$ of only $1.5^{\circ} \mathrm{C}$ ) (10).

AFLP analysis of $\boldsymbol{A}$. lwoffii. Bouvet and Grimont (12) originally described the genomic species 8 and 9 as two distinct taxa. However, because the type strain of $A$. lwoffii fell into DG 8 and genomic species 8 and 9 could not be separated by phenotypic tests, $A$. lwoffii became synonymous with DG 8-9 (with DG 8 as $A$. lwoffii sensu stricto). The unification of DGs 8 and 9 was justified by additional DNA hybridization experiments

TABLE 2. Linkage levels of Acinetobacter DGs according to AFLP

\begin{tabular}{llcc}
\hline \multicolumn{1}{c}{ DG $^{a}$} & \multicolumn{1}{c}{ Species name } & $\begin{array}{c}\text { No. of } \\
\text { strains }\end{array}$ & $\begin{array}{c}\text { Linkage } \\
\text { level }(\%)^{b}\end{array}$ \\
\hline 1 & A. calcoaceticus & 7 & $52.5 \pm 2.6$ \\
2 & A. baumannii & 34 & $57.4 \pm 5.0$ \\
3 & A. haemolyticus & 12 & $58.1 \pm 6.2$ \\
4 & A. junii & 7 & $50.6 \pm 3.2$ \\
5 & & 5 & $54.7 \pm 7.5$ \\
6 & A. johnsonii & 2 & $55.6 \pm 0.0$ \\
7 & Excluding LUH 540 & 9 & $29.4 \pm 5.5$ \\
& A. lwoffi & 8 & $44.7 \pm 5.5$ \\
8-9 & & $13 / 6$ & $51.7 \pm 7.6$ \\
10 & & 3 & $51.9 \pm 0.9$ \\
11 & A. radioresistens & 7 & $38.1 \pm 4.4$ \\
12 & & 8 & $60.3 \pm 6.6$ \\
13BJ & & 8 & $39.5 \pm 6.2$ \\
14BJ & & 3 & $40.6 \pm 6.3$ \\
15BJ & & 2 & $74.1 \pm 0.0$ \\
16BJ & & 2 & $48.5 \pm 5.9$ \\
17BJ & & 11 & $42.4 \pm 0.0$ \\
13TU & & 7 & $60.5 \pm 2.0$ \\
14TU & & 2 & $33.3 \pm 1.9$ \\
15TU & & $8 / 7$ & $33.6 \pm 0.0$ \\
13BJ-14TU ${ }^{d}$ & & 2 & $49.5 \pm 0.8$ \\
UG1 & & 2 & $50.2 \pm 0.0$ \\
UG2 $^{e}$ & LUH 1469, 1470 & LUH 1471, 1472 & $50.8 \pm 2.2$ \\
UG3 $^{f}$ & LUH 1737, 1740-1742 & 4 & \\
\hline
\end{tabular}

${ }^{a}$ Genomic species (DGs) are numbered according to Bouvet and Grimont (12) (no suffix), Bouvet and Jeanjean (11) (suffix BJ), or Tjernberg and Ursing (65) (suffix TU).

${ }^{b}$ Average linkage levels of genomic species are expressed as the percent Pearson product moment correlation coefficient at the first branching point of each cluster and are indicated with the standard deviation as calculated by GelCompar.

${ }^{c}$ DGs 8 and 9 form one species according to Tjernberg and Ursing (65).

${ }^{d}$ Assuming the independently described DGs 13BJ and 14TU unite in one genomic species $(5,44,65)$ (see text).

${ }^{c}$ Isolates that belong to the Acb complex but are distinct from any of the four genomic species described within this complex (32).

${ }^{f}$ Ungrouped strains described by Bouvet and Jeanjean (11). 


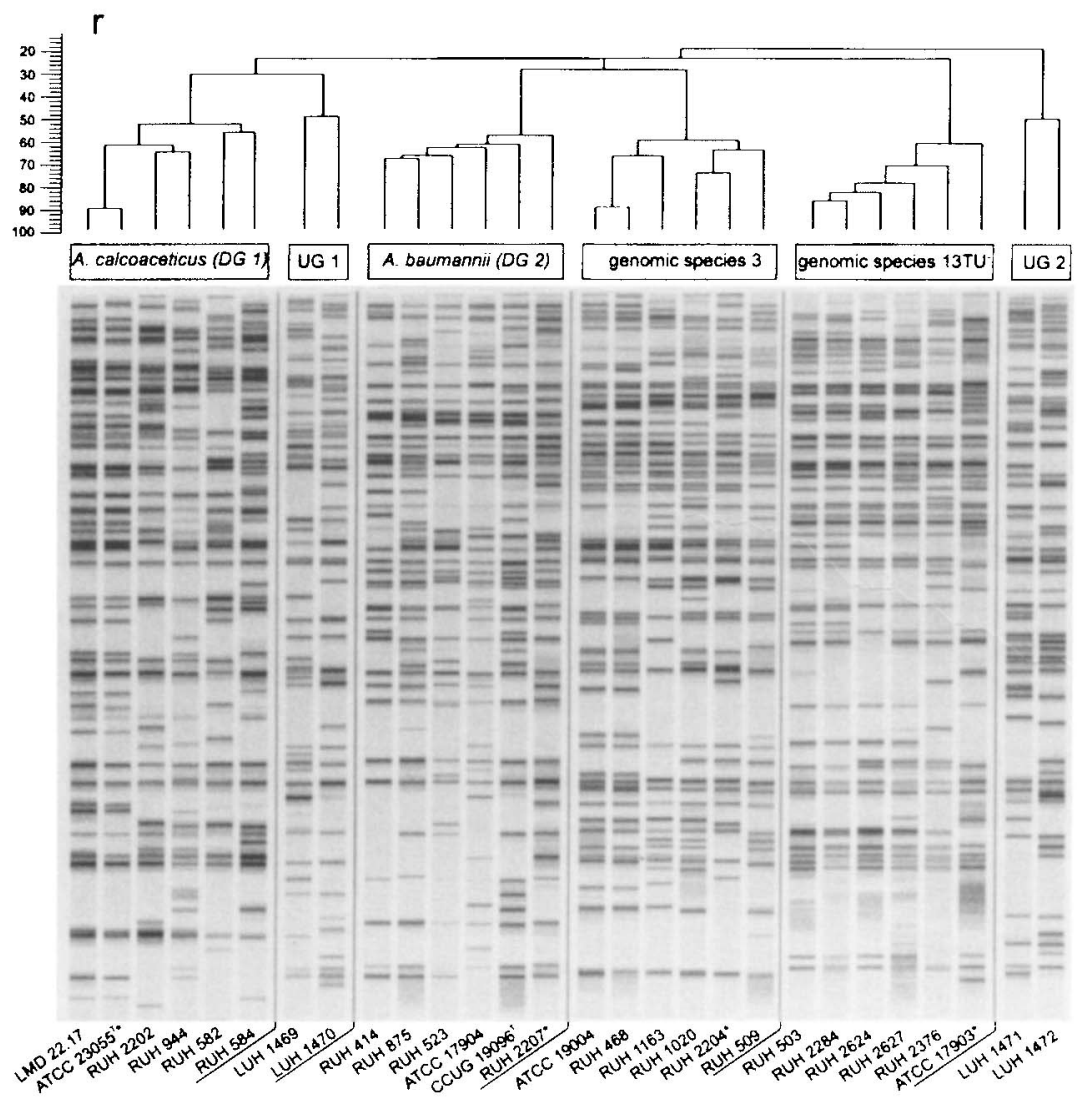

FIG. 2. Chromosomal AFLP patterns of some of the Acinetobacter strains representing the six currently known genomic species within the Acb complex. $r$, product moment correlation coefficient; *, DNA hybridization reference strain. The dendrogram was constructed by using UPGMA.

(65). A total of $19 A$. lwoffii strains were analyzed by AFLP. These strains formed a homogeneous group at a linkage level of $(51.7 \pm 7.6) \%$ similarity (Fig. 1$)$, with AFLP patterns of NCTC $5866^{\mathrm{T}}$ (DG 8) (65) and CIP A162 (DG 9) (12) nearly identical $(r>0.9)$ (Fig. 3a), illustrating the identity of the two DGs.

AFLP analysis of $A$. radioresistens. In 1979, an acinetobacter displaying elevated resistance against gamma rays was isolated from a cotton sample (42). This strain (FO-1) and other radioresistant Acinetobacter strains isolated from soil were characterized by phenotypic tests and DNA-pairing experiments $(47,48)$, leading to the proposal in 1988 of a new species, $A$. radioresistens (49), with the FO-1 strain as the type strain. The following year, based on DNA hybridization data, strains FO- ${ }^{\mathrm{T}}$ (41) and SEIP 12.81 (12) were grouped together with 30 clinical isolates in a single genomic species, DG 12 (65). AFLP analysis fully corroborated this finding by grouping strains $\mathrm{FO}-$ $1^{\mathrm{T}}$, SEIP 12.81 , and six of the 30 clinical $A$. radioresistens strains as a very homogeneous species displaying a high linkage level of $(60.3 \pm 6.6) \%$ similarity (Fig. 1).

AFLP analysis of Acinetobacter species without nomenclatural rank. (i) DGs 6, 10, and 11 sensu Bouvet \& Grimont 1986. Besides DG 3, three other genomic species from the original Bouvet and Grimont study (12) remained unnamed. Genomic species 6 is difficult to distinguish phenotypically from $A$. haemolyticus $(5,44)$ except for the inability of DG 6 strains to metabolize 4-aminobutyrate $(5,12)$. Only two strains of DG 6 were available for AFLP analysis, which linked them at $(55.6 \pm 0.0) \%$ similarity. Their AFLP patterns did not show any resemblance to the banding patterns obtained for $A$. hae- molyticus (with an interspecific similarity below 12\%; AFLP patterns not shown). The genomic species 10 and 11 share a number of genotypical $(12,67,75)$ and phenotypical $(5,44)$ features but clearly represent two separate taxa. This could be confirmed by AFLP analysis, which grouped 3 DG 10 and 10 DG 11 strains in two separate clusters, with linkage levels of $(51.9 \pm 0.9)$ and $(38.1 \pm 4.4) \%$ similarity, respectively (Fig. 1), and an interspecific linkage below $15 \%$.

(ii) DGs 13BJ to 17BJ. In 1989, Bouvet and Jeanjean (11) characterized 27 proteolytic Acinetobacter strains that were phenotypically different from the 12 previously described $\mathrm{Aci}$ netobacter species (12). Twenty of these strains could be allocated to five distinct DNA hybridization groups (genomic species $13 \mathrm{BJ}$ to $17 \mathrm{BJ}$ ), of which $15 \mathrm{BJ}, 16 \mathrm{BJ}$, and $17 \mathrm{BJ}$ appeared to be more closely related to each other than to any other genomic species in the genus. All 27 strains were included in this study and subjected to AFLP fingerprinting. The 20 strains that represented the five DGs $13 \mathrm{BJ}$ to $17 \mathrm{BJ}$ formed five corresponding AFLP clusters at an average linkage level of approximately 40 to $74 \%$ (Fig. 1 and Table 2). The remaining seven strains could not be assigned to any of the currently described genomic species (not all results shown; see below). The species 13BJ appeared to be heterogeneous, because its reference strain, LUH 1717 (= CIP 64.2 = ATCC 17905), together with strain LUH 1719 (related to the reference strain by an AFLP-based correlation of $70.2 \%$ ), were linked with the other 13BJ strains $(r=[74.1 \pm 4.7] \%)$ at only $(39.5 \pm 6.2) \%$ (these linkage levels were found by a separate numerical analysis including only 13BJ strains [i.e., excluding 14TU strains]; dendrogram not shown; see below). 
a)
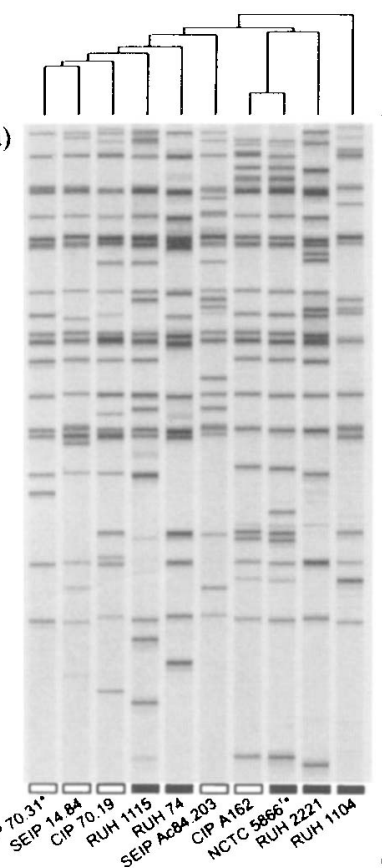

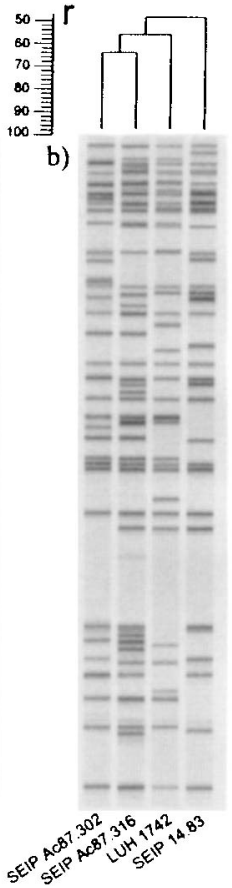

FIG. 3. (a) AFLP patterns of Acinetobacter strains belonging to genomic species 8 (A. lwoffi sensu stricto) ( $\square$ ) and 9 ( $\square$ ) form one homogeneous AFLP cluster. (b) AFLP patterns of four ungrouped Acinetobacter strains that were previously described by Bouvet and Jeanjean (11) and that may be part of a new genomic species. *, DNA hybridization reference strain. All strains are listed in Table 1 . The scale represents the Pearson correlation coefficient $(r)$. Dendrograms were constructed by using UPGMA

(iii) DGs 14TU to 15TU. An independent DNA hybridization study with strain RUH 2216 as a reference (65) allocated the 13BJ reference strain, CIP 64.2 (= ATCC 17905) (see above), to DG 14TU. This finding, which could be fully corroborated by phenotypic results $(5,44)$, suggested that DGs $13 \mathrm{BJ}$ and $14 \mathrm{TU}$ may represent the same genomic species. We analyzed seven strains of DG 14TU by AFLP fingerprinting and found that five of the seven strains, including reference strain RUH 2216 (Table 1), linked tightly together at (87.3 \pm $1.5) \%$ similarity (dendrogram not shown). However, the remaining two strains, RUH 2217 and RUH 2218 (= ATCC $17905)$, linked with the other five strains at only $(33.3 \pm 1.9)$ and $(35.4 \pm 1.5) \%$, respectively. It is interesting to note that these two strains displayed a relatively low degree of DNA relatedness with the 14TU reference strain, RUH 2216 (65), and that the cell envelope protein profiles of strains RUH 2216 and RUH 2217, although similar, were clearly distinguishable from each other (18). When AFLP data obtained for DGs $13 \mathrm{BJ}$ and $14 \mathrm{TU}$ are combined in one dendrogram, three subgroups, A, B, and C, linking at similarity levels of $(69.5 \pm 0.6)$, $(87.3 \pm 1.5)$, and $(70.6 \pm 4.5) \%$, respectively, appear to exist within the 13BJ-14TU union (Fig. 4). Recently, nine strains of the 13BJ-14TU group were analyzed by tRNA spacer fingerprinting (24), but only one strain of the 14TU group, ATCC 17905 , was included and the typing results obtained on these strains were inconsistent with their DG affiliations. Also, these data were not in agreement with the $\mathrm{ABC}$ subdivision of the 13BJ-14TU group as suggested by AFLP analysis. An earlier study with ARDRA (67) included only three 14TU strains and none of the originally described $13 \mathrm{BJ}$ strains, but a recent continuation of this work (17) eventually led to the analysis of all 13BJ and 14TU strains listed in Table 1. Intriguingly, these new ARDRA data also seem to point out incongruities within the 13BJ-14TU group. Clearly, additional DNA hybridization data combined with a polyphasic approach using various genotypic and phenotypic methods is needed to unravel the precise structure of the 13BJ-14TU group. Genomic species 15TU was represented by only two strains (Table 1 ), which were linked by AFLP analysis at $50.6 \%$ similarity (Fig. 2).

(iv) A novel Acinetobacter genomic species? Seven of the 27 proteolytic Acinetobacter strains described in 1989 by Bouvet and Jeanjean (11) could not be characterized by DNA hybridization. These strains showed a 28 to $60 \%$ DNA relatedness with genomic species 13BJ to 17BJ (11). Unfortunately, further taxonomic information on these strains is scarce, although very recently the same seven strains were analyzed by ARDRA (17). AFLP analysis revealed that three of the seven strains remained ungrouped and did not link to any other Acinetobacter strain included in the present study (results not shown). The other four strains (LUH 1737 and LUH 1740 to 1742) (Table 1) convincingly grouped in a separate AFLP cluster, UG3, at $(50.8 \pm 2.2) \%$ similarity (Fig. 1). Their AFLP patterns are given in Fig. 3b. The overall data presented here and in previous reports $(36,39)$ on the ability of AFLP to discriminate genomic species strongly suggest that AFLP cluster UG3 represents a new genomic species in the genus Acinetobacter. This concept was recently further strengthened by the fact that all four strains displayed the same unique ARDRA profile (17). Nonetheless, additional DNA-DNA hybridization experiments must be performed to confirm these results.

Conclusions. The entire taxonomic structure of the genus Acinetobacter could be resolved by a single method, AFLP. By

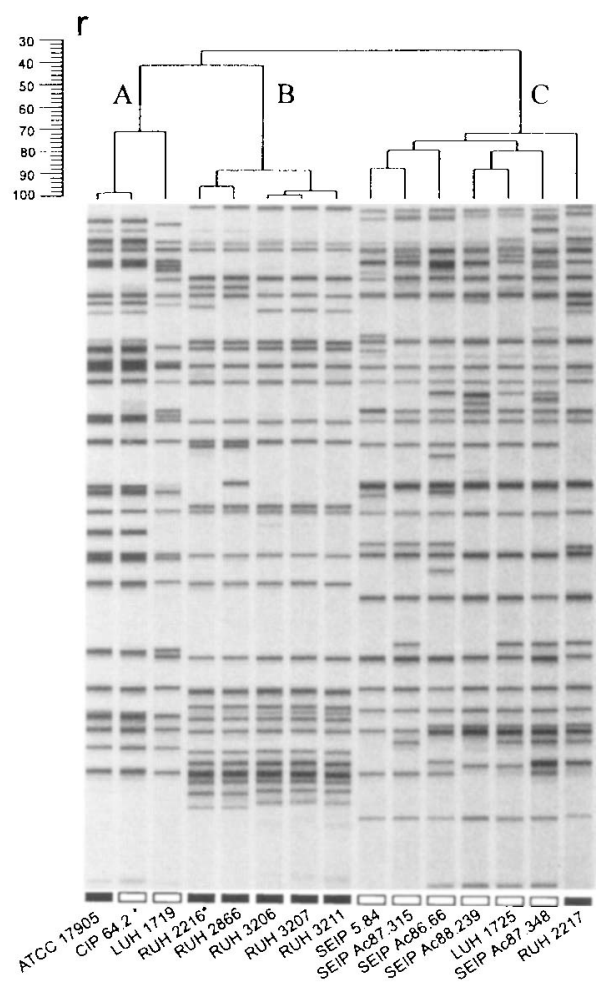

FIG. 4. AFLP analysis of Acinetobacter strains belonging to the genomic species 13BJ ( $\square$ ) and 14TU ( $\square$ ). Strains displaying highly similar AFLP patterns $(r \geq 69 \%)$ could be found in three separate subclusters, A, B, and C. The scale represents the Pearson product moment correlation coefficient $(r)$. * DNA hybridization reference strain. The dendrogram was constructed by using UPGMA. 
using this method, all genomic species currently known in the genus as distinct taxa were delineated correctly and individual strains within a species were easily distinguished, although interspecific relatedness could not be addressed by AFLP. Identification of acinetobacters at the genomic species level is often difficult and usually requires the determination of DNA homology values by DNA-DNA hybridization. These data, however, cannot be stored as reference entities for future comparative analyses. Consequently, each new Acinetobacter isolate that needs unambiguous identification at the genomic species level will require additional hybridization experiments. This is not the case for AFLP fingerprints, which after storage and processing by computer, can be used to establish identification libraries (37). In this context, AFLP should be seen as an ideal preliminary screening method for large numbers of isolates, with the ultimate confirmatory role reserved for DNA hybridization analysis, in which DNA-DNA pairing experiments can be more directed.

\section{ACKNOWLEDGMENTS}

This research was carried out in the framework of contract G.O.A. 91/96-2 with the Ministerie van de Vlaamse Gemeenschap, Bestuur Wetenschappelijk Onderzoek (Belgium). In addition, part of this research was funded by the Stichting Microbiologie Leiden.

Peter Gerner-Smidt and Peter Kämpfer are thanked for their generous provision of strains. We are indebted to Barbara van Harsselaar for her dedicated review of strain specifications and gratefully thank Dirk Dewettinck for the meticulously prepared figures. Finally, we also acknowledge C.P.A. van Boven for his invaluable advice and continuous support.

\section{REFERENCES}

1. Baumann, P. 1968. Isolation of Acinetobacter from soil and water. J. Bacteriol. 96:39-42.

2. Beck-Sagué, C., W. Jarvis, J. Brook, D. Culver, A. Potts, E. Gay, B. Shotts, B. Hill, R. Anderson, and M. Weinstein. 1990. Epidemic bacteremia due to Acinetobacter baumannii in five intensive care units. Am. J. Epidemiol. 132: $723-733$.

3. Bergogne-Bérézin, E., M. L. Joly-Guillou, and J. F. Vieu. 1987. Epidemiology of nosocomial infections due to Acinetobacter calcoaceticus. J. Hosp. Infect. 10:105-113.

4. Bergogne-Bérézin, E., and K. J. Towner. 1996. Acinetobacter spp. as nosocomial pathogens: microbiological, clinical, and epidemiological features. Clin. Microbiol. Rev, 9:148-165.

5. Bernards, A. T., L. Dijkshoorn, J. van der Toorn, B. R. Bochner, and C. P. A. van Boven. 1995. Phenotypic characterisation of Acinetobacter strains of 13 DNA-DNA hybridisation groups by means of the Biolog system. J. Med. Microbiol. 42:113-119.

6. Bernards, A. T., J. van der Toorn, C. P. A. van Boven, and L. Dijkshoorn. 1996. Evaluation of the ability of a commercial system to identify Acinetobacter genomic species. Eur. J. Clin. Microbiol. Infect. Dis. 15:303-308.

7. Bernards, A. T., A. J. de Beaufort, L. Dijkshoorn, and C. P. A. van Boven. 1997. Outbreak of septicaemia in neonates caused by Acinetobacter junit investigated by amplified ribosomal DNA restriction analysis (ARDRA) and four typing methods. J. Hosp. Infect. 35:129-140.

8. Bifulco, J. M., J. J. Shirey, and G. K. Bissonnette. 1989. Detection of Acinetobacter spp. in rural drinking water supplies. Appl. Environ. Microbiol. 55:2214-2219.

9. Bond, P. L., P. Hugenholtz, J. Keller, and L. L. Blackall. 1995. Bacterial community structures of phosphate-removing and non-phosphate-removing activated sludges from sequencing batch reactors. Appl. Environ. Microbiol 61:1910-1916.

10. Bonting, C. F. C., B. M. F. Willemsen, W. Akkermans-van Vliet, P. J. M. Bouvet, G. J. J. Kortsee, and A. J. B. Zehnder. 1992. Additional characteristics of the polyphosphate-accumulating Acinetobacter strain $210 \mathrm{~A}$ and its identification as Acinetobacter. FEMS Microbiol. Ecol. 102:57-64.

11. Bouvet, P. J. M., and S. Jeanjean. 1989. Delineation of new proteolytic genomic species in the genus Acinetobacter. Res. Microbiol. 140:291-299.

12. Bouvet, P. J. M., and P. A. D. Grimont. 1986. Taxonomy of the genus Acinetobacter with the recognition of Acinetobacter baumannii sp. nov., Acinetobacter haemolyticus sp. nov., Acinetobacter johnsonii, sp. nov., and Acinetobacter junii sp. nov. and emended descriptions of Acinetobacter calcoaceticus and Acinetobacter lwoffii. Int. J. Syst. Bacteriol. 36:228-240.

13. Bouvet, P. J. M., and P. A. D. Grimont. 1987. Identification and biotyping of clinical isolates of Acinetobacter. Ann. Inst. Pasteur 138:569-578.
14. Bouvet, P. J. M., and S. Jeanjean. 1995. Differentiation of Acinetobacter calcoaceticus sensu stricto from related Acinetobacter species by electrophoretic polymorphism of malate dehydrogenase, glutamate dehydrogenase and catalase. Res. Microbiol. 146:773-785.

15. Brisou, J., and A. R. Prévot. 1954. Etudes de systématique bactérienne. X. Révision des espèces réunies dans le genre Achromobacter. Ann. Inst. Pasteur 86:722-728.

16. Crombach, W. H. J., L. Dijkshoorn, M. van Noort-Klaassen, J. Niessen, and G. van Knippenbert-Gordebeke. 1989. Control of an epidemic spread of multi-resistant Acinetobacter calcoaceticus in a hospital. Intensive Care Med. 15:166-170.

17. Dijkshoorn, L., B. van Harsselaar, I. Tjernberg, P. J. M. Bouvet, and M. Vaneechoutte. Submitted for publication.

18. Dijkshoorn, L., I. Tjernberg, B. Pot, M. F. Michel, J. Ursing, and K. Kersters. 1990. Numerical analysis of cell envelope protein profiles of Acinetobacter strains classified by DNA-DNA hybridization. Syst. Appl. Microbiol. 13:338-344.

19. Dijkshoorn, L., and J. van der Toorn. 1992. Acinetobacter species: which do we mean? Clin. Infect. Dis. 15:748-749.

20. Dijkshoorn, L. 1996. Microbiology, epidemiology, infections, management, p. 37-69. In E. Bergogne-Bérézin, M. L. Joly-Guillou, and K. J. Towner (ed.), Acinetobacter. CRC Press, New York, N.Y.

21. Dijkshoorn, L., H. M. Aucken, P. Gerner-Smidt, P. Janssen, M. E. Kaufmann, J. Garaizar, J. Ursing, and T. L. Pitt. 1996. Comparison of outbreak and nonoutbreak Acinetobacter baumannii strains by genotypic and phenotypic methods. J. Clin. Microbiol. 34:1519-1525.

22. Dolzani, L., E. Tonin, C. Lagatolla, L. Prandin, and C. Monti-Bragadin. 1995. Identification of Acinetobacter isolates in the $A$. calcoaceticus-A. baumannii complex by restriction analysis of the 16S-23S rRNA intergenic spacer sequences. J. Clin. Microbiol. 33:1108-1113.

23. Duncan, A., G. E. Vasiliadis, R. C. Bayly, and J. W. May. 1988. Genospecies of Acinetobacter isolated from activated sludge showing removal of phosphate during pilot-scale treatment of sewage. Biotechnol. Lett. 10:831-836.

24. Ehrenstein, B., A. T. Bernards, L. Dijkshoorn, P. Gerner-Smidt, K. J. Towner, P. J. M. Bouvet, F. D. Daschner, and H. Grundmann. 1996. Acinetobacter species identification by using tRNA spacer fingerprinting. J. Clin. Microbiol. 34:2414-2420.

25. Enright, M. C., P. E. Carter, I. A. MacLean, and H. McKenzie. 1994. Phylogenetic relationships between some members of the genera Neisseria, Acinetobacter, Moraxella, and Kingella based on partial 16S ribosomal DNA sequence analysis. Int. J. Syst. Bacteriol. 44:387-391.

26. Eribo, B. E., and J. M. Jay. 1985. Incidence of Acinetobacter spp. and other gram-negative, oxidase-negative bacteria in fresh and spoiled ground beef. Appl. Environ. Microbiol. 49:256-257.

27. Fagon, J.-Y., J. Chastre, Y. Domart, J.-L. Trouillet, J. Pierre, C. Darne, and C. Gilbert. 1989. Nosocomial pneumonia in patients receiving continuous mechanical ventilation. Am. Rev. Respir. Dis. 139:877-884.

28. Gennari, M., and P. Lombardi. 1993. Comparative characterization of $A c i-$ netobacter strains isolated from different foods and clinical sources. Zentralbl. Bakteriol. 279:553-564.

29. Gerner-Smidt, P. 1987. Endemic occurrence of Acinetobacter calcoaceticus biovar anitratus in an intensive care unit. J. Hosp. Infect. 10:265-272.

30. Gerner-Smidt, P. 1992. Ribotyping of the Acinetobacter calcoaceticus-Acinetobacter baumannï complex. J. Clin. Microbiol. 30:2680-2685.

31. Gerner-Smidt, P., and W. Frederiksen. 1993. Acinetobacter in Denmark. I. Taxonomy, antibiotic susceptibility, and pathogenicity of 112 clinical strains. APMIS 101:815-825.

32. Gerner-Smidt, P., and I. Tjernberg. 1993. Acinetobacter in Denmark. II. Molecular studies of the Acinetobacter calcoaceticus-Acinetobacter baumannii complex. APMIS 101:826-832.

33. Gerner-Smidt, P., I. Tjernberg, and J. Ursing. 1991. Reliability of phenotypic tests for identification of Acinetobacter species. J. Clin. Microbiol. 29:277-282.

34. Glew, R. H., R. C. Moellering, and L. J. Kunz. 1977. Infections with $\mathrm{Aci}$ netobacter calcoaceticus (Herellea vaginicola): clinical and laboratory studies. Medicine 56:79-97.

35. Horrevorts, A., K. Bergman, L. Kollée, I. Breuker, I. Tjernberg, and L. Dijkshoorn. 1995. Clinical and epidemiological investigations of Acinetobacter genomospecies 3 in a neonatal intensive care unit. J. Clin. Microbiol. 33:1567-1572.

36. Huys, G., R. Coopman, P. Janssen, and K. Kersters. 1996. High-resolution genotypic analysis of the genus Aeromonas by AFLP fingerprinting. Int. J. Syst. Bacteriol. 46:572-580.

37. Huys, G., I. Kersters, R. Coopman, P. Janssen, and K. Kersters. 1996. Genotypic diversity among Aeromonas recovered from drinking water production plants as revealed by AFLPTM analysis. Syst. Appl. Microbiol. 19: $428-435$.

38. Ibrahim, A., P. Gerner-Smidt, and W. Liesack. 1997. Phylogenetic relationship of the twenty-one DNA groups of the genus Acinetobacter as revealed by 16 S ribosomal DNA sequence analysis. Int. J. Syst. Bacteriol. 47:837-841.

39. Janssen, P., R. Coopman, G. Huys, J. Swings, M. Bleeker, P. Vos, M. Zabeau, and K. Kersters. 1996. Evaluation of the DNA fingerprinting 
method AFLP as a new tool in bacterial taxonomy. Microbiology (Reading) 142: 1881-1893.

40. Janssen, P., and L. Dijkshoorn. 1996. High resolution DNA fingerprinting of Acinetobacter outbreak strains. FEMS Microbiol. Lett. 142:191-194.

41. Juni, E. 1984. Genus III. Acinetobacter Brisou et Prévot 1954, $727^{\mathrm{AL}}$, p. 303-307. In N. R. Krieg and J. G. Holt (ed.), Bergey's manual of systematic bacteriology, vol. 1. The Williams \& Wilkins Co., Baltimore, Md.

42. Kairiyama, E., Y. Nishimura, and H. Iizuka. 1979. Radioresistance of an Acinetobacter species. J. Gen. Appl. Microbiol. 25:401-406.

43. Kämpfer, P. 1993. Grouping of Acinetobacter genomic species by cellular fatty acid composition. Med. Microbiol. Lett. 2:394-400.

44. Kämpfer, P., I. Tjernberg, and J. Ursing. 1993. Numerical classification and identification of Acinetobacter genomic species. J. Appl. Bacteriol. 75:259268.

45. Knight, G. C., S. A. McDonnell, R. J. Seviour, and J. A. Soddell. 1993. Identification of Acinetobacter isolates using the Biolog identification system. Lett. Appl. Microbiol. 16:261-264.

46. Lessel, E. F. 1971. Minutes of the International Committee on Nomenclature of Bacteria subcommittee on the taxonomy of Moraxella and allied bacteria. Int. J. Syst. Bacteriol. 21:213-214.

47. Nishimura, Y., E. Kairiyama, M. Shimadzu, and H. Iizuka. 1981. Characterization of radiation-resistant Acinetobacter. Z. Allg. Mikrobiol. 21:125130.

48. Nishimura, Y., M. Kano, T. Ino, H. Iizuka, Y. Kosako, and T. Kaneko. 1987. Deoxyribonucleic acid relationship among the radiation-resistant Acinetobacter and other Acinetobacter. J. Gen. Appl. Microbiol. 33:371-376.

49. Nishimura, Y., T. Ino, and H. Iizuka. 1988. Acinetobacter radioresistens sp. nov. isolated from cotton and soil. Int. J. Syst. Bacteriol. 38:209-211.

50. Noble, W. C., and D. G. Pitcher. 1978. Microbial ecology of the human skin. Adv. Microb. Ecol. 2:245-289.

51. Nowak, A., A. Burkewicz, and J. Kur. 1995. PCR differentiation of seventeen genospecies of Acinetobacter. FEMS Microbiol. Lett. 126:181-188.

52. Nowak, A., and J. Kur. 1996. Differentiation of seventeen genospecies of Acinetobacter by multiplex polymerase chain reaction and restriction fragment length polymorphism analysis. Mol. Cell. Probes 10:405-411.

53. Nowak, A., and J. Kur. 1995. Genomic species typing of acinetobacters by polymerase chain reaction amplification of the $r e c A$ gene. FEMS Microbiol. Lett. 130:327-332.

54. Pagel, J. E., and P. L. Seyfried. 1976. Numerical taxonomy of aquatic Acinetobacter isolates. J. Gen. Microbiol. 95:220-232.

55. Pitcher, D. G., N. A. Saunders, and R. J. Owen. 1989. Rapid extraction of bacterial genomic DNA with guanidium thiocyanate. Lett. Appl. Microbiol. 8:151-156.

56. Rainey, F., E. Lang, and E. Stackebrandt. 1994. The phylogenetic structure of the genus Acinetobacter. FEMS Microbiol. Lett. 124:349-354.

57. Rosenthal, S., and I. B. Tager. 1975. Prevalence of Gram-negative rods in the normal pharyngeal flora. Ann. Intern. Med. 83:355-357.

58. Rossau, R., A. Van Landschoot, W. Mannheim, and J. De Ley. 1986. Interand intrageneric similarities of ribosomal ribonucleic acid cistrons of the Neisseriaceae. Int. J. Syst. Bacteriol. 36:323-332.

59. Rossau, R., A. Van Landschoot, M. Gillis, and J. De Ley. 1991. Taxonomy of Moraxellaceae fam. nov., a new bacterial family to accomodate the genera Moraxella, Acinetobacter, and Psychrobacter and related organisms. Int. J. Syst. Bacteriol. 41:310-319.

60. Sakata, H., K. Fujita, S. Maruyama, H. Kakehashi, Y. Mori, and H. Yo- shioka. 1989. Acinetobacter calcoaceticus biovar anitratus septicaemia in a neonatal intensive care unit: epidemiology and control. J. Hosp. Infect. 14:15-22.

61. Seifert, H., and P. Gerner-Smidt. 1995. Comparison of ribotyping and pulsed-field gel electrophoresis for molecular typing of Acinetobacter isolates. J. Clin. Microbiol. 33:1402-1407.

62. Sneath, P. H. A., and R. R. Sokal. 1973. Numerical taxonomy: the principles and practice of numerical classification. W. H. Freeman, San Francisco, Calif.

63. Snelling, A. M., P. Gerner-Smidt, P. M. Hawkey, J. Heritage, P. Parnell, C. Porter, A. R. Bodenham, and T. Inglis. 1996. Validation of use of whole-cell repetitive extragenic palindromic sequence-based PCR (REP-PCR) for typing strains belonging to the Acinetobacter calcoaceticus-Acinetobacter baumannii complex and application of the method to the investigation of a hospital outbreak. J. Clin. Microbiol. 34:1193-1202.

64. Soddell, J. A., A. M. Beacham, and R. J. Seviour. 1993. Phenotypic identification of non-clinical isolates of Acinetobacter species. J. Appl. Bacteriol. 74:210-214.

65. Tjernberg, I., and J. Ursing. 1989. Clinical strains of Acinetobacter classified by DNA-DNA hybridization. APMIS 79:595-605.

66. Towner, K. J. 1992. The genus Acinetobacter, p. 3137-3143. In A. Balows, H. G. Trüper, M. Dworkin, W. Harder, and K.-H. Schleifer (ed.), The prokaryotes, 2nd ed. Springer-Verlag, New York, N.Y.

67. Vaneechoutte, M., L. Dijkshoorn, I. Tjernberg, A. Elaichouni, P. De Vos, G. Claeys, and G. Verschraegen. 1995. Identification of Acinetobacter genomic species by amplified ribosomal DNA restriction analysis. J. Clin. Microbiol. 33:11-15.

68. Vaneechoutte, M., A. Elaichouni, K. Maquelin, G. Claeys, A. Van Liedekerke, H. Louagie, G. Verschraegen, and L. Dijkshoorn. 1995. Comparison of arbitrarily primed polymerase chain reaction and cell envelope protein electrophoresis for analysis of Acinetobacter baumannii and Acinetobacter junii outbreaks. Res. Microbiol. 146:457-465.

69. Van Landschoot, A., R. Rossau, and J. De Ley. 1986. Intrageneric and intergeneric similarities of the ribosomal ribonucleic acid cistrons of $\mathrm{Aci}$ netobacter. Int. J. Syst. Bacteriol. 36:150-160.

70. Vos, P., R. Hogers, M. Bleeker, M. Reijans, T. van de Lee, M. Hornes, A. Freijters, J. Pot, J. Peleman, M. Kuiper, and M. Zabeau. 1995. AFLP: a new technique for DNA fingerprinting. Nucleic Acids Res. 23:4407-4414.

71. Wallner, G., R. Erhart, and R. Amann. 1995. Flow cytometric analysis of activated sludge with rRNA-targeted probes. Appl. Environ. Microbiol. 61: 1859-1866.

72. Weaver, R. E., and L. A. Actis. 1994. Identification of Acinetobacter species. J. Clin. Microbiol. 32:1833.

73. Wiedman-Al-Ahmad, M., H.-V. Tichy, and G. Schön. 1994. Characterization of Acinetobacter type strains and isolates obtained from wastewater treatment plants by PCR fingerprinting. Appl. Environ. Microbiol. 60:4066-4071.

74. Woese, C. R., W. G. Weisburg, C. M. Hahn, B. J. Paster, L. B. Zablen, B. J Lewis, T. J. Macke, W. Ludwig, and E. Stackebrandt. 1985. The phylogeny of purple bacteria: the gamma subdivision. Syst. Appl. Microbiol. 6:25-33.

75. Yamamoto, S., and S. Harayama. 1996. Phylogenetic analysis of Acinetobacter strains based on the nucleotide sequences of $\operatorname{gyr} B$ genes and on the amino acid sequences of their products. Int. J. Syst. Bacteriol. 46:506-511.

76. Zabeau, M., and P. Vos. 1993. Selective restriction fragment amplification: a general method for DNA fingerprinting. European Patent Office publication 0534858 A1. European Patent Office, Munich, Germany. 